\title{
Climatology of Intrusions into the Tropical Upper Troposphere
}

\author{
Darryn W. Waugh \\ Department of Earth and Planetary Science, Johns Hopkins University, Baltimore, MD.
}

\section{Lorenzo M. Polvani}

Department of Applied Physics and Applied Mathematics, Columbia University, New York, NY.

\begin{abstract}
Regions of upper tropospheric equatorial westerly winds, observed over the Pacific and Atlantic Oceans during northern fall to spring, are important for extratropicaltropical interactions. This paper focuses on one feature of these "westerly ducts" that has received relatively little attention to date: the occurrence of Rossby wave breaking events that transport tongues of extratropical air deep into the tropics, mix tropical and subtropical air, and can affect deep convection. A climatology of these "intrusion" events formed from 20 years of meteorological analyses shows a strong dependence on the basic-state flow. Notably, intrusion events are found to occur almost exclusively within westerly ducts, with more events in the presence of stronger equatorial westerlies. It is also found that there is strong interannual variability in the frequency of Pacific events, with fewer events during the warm phases of ENSO (consistent with the changes in the basic flow). Since these intrusion events laterally mix trace constituents and have been linked to tropical convection, their spatial and temporal variability may cause related variability in the distribution of trace constituents and tropical convection.
\end{abstract}

\section{Introduction}

A well-known climatological feature of the upper troposphere (UT) during northern fall through spring is the existence of regions of equatorial westerlies over the $\mathrm{Pa}$ cific and Atlantic Oceans. These "westerly ducts" are important for extratropical-tropical interactions. In the linear regime, Rossby waves are able to propagate through westerlies, and thus westerly ducts are preferred locations for cross-equatorial wave propagation [Webster and Holton, 1982; Tomas and Webster, 1994; Yang and Hoskins, 1996]. By contrast, when Rossby waves are of sufficiently large amplitude "wave breaking" [McIntyre and Palmer, 1983] may occur within the westerlies, resulting in reduced meridional propagation and mixing within equatorial regions [Waugh et al., 1994; Brunet and Haynes, 1996]. Evidence for this wave breaking can be seen in maps of potential vorticity (PV) from meteorological analyses, of which an example is given in Figure 1 (see also Kiladis and Weickmann [1992], Tomas and Webster [1994], Numaguti [1995]).

In Figures 1b-1d a disturbance can be seen propagating along the tropopause and subsequently compressing

Copyright 2000 by the American Geophysical Union.

Paper number 2000GL012250

0094-8276/00/2000GL012250\$05 00 zonally and amplifying meridionally as it enters the weak zonal winds north of the Pacific westerly duct (see Figure 1a). This leads to the generation of a thin tongue of high PV intruding into the tropics (Figure 1e), that lasts 2 days. As this intrusion decays, another event can be seen beginning upstream (Figure 1f, $220^{\circ} \mathrm{E}$ ). Intrusion events which transport stratospheric air deep into the tropical UT, such as the one presented here, are special cases of the more general wave breaking events along the subtropical tropopause examined by Postel \& Hitchman [1999].

Because of their penetration deep into the tropics, intrusion events can potentially have a large impact on the UT distribution of trace constituents. These intrusions may mix stratospheric air, with low water vapor and high ozone, into the tropical UT. Also, the anticyclonic circulation upstream of the intruded tongue can result in the transport of moist air from equatorial regions into the dry subtropics [Pierrehumbert, 1998]. Furthermore, layers of dry air measured in the tropical Pacific during the TOGA-COARE field campaign have been linked to subtropical Rossby wave breaking events [Yoneyama and Parsons, 1999]. Intrusion events can also been seen in TOMS total ozone images ( $P$. Newman, person. comm.), and may contribute to the observed increase in ozone below tropical tropospause [Folkins et al., 1999]. Finally, beyond lateral mixing, intrusions of high PV into the tropics have been linked with deep convection in the tropical central and eastern Pacific [Kiladis and Weickmann, 1992; Kiladis, 1998].

Although previous studies have noted the occurrence of intrusion events, a detailed analysis of their frequency is still missing. We thus present here a 20-year climatology of UT intrusions, and examine both the spatial and temporal variations of these events (and the background flow).

\section{Data and Analysis}

NCEP/NCAR reanalyses [Kalnay et al., 1996] from 1980 to 1999 are used to examine the structure and occurrence of intrusions of stratospheric air into the tropical upper troposphere. $\mathrm{PV}$ on the $350 \mathrm{~K}$ isentropic surface $(\sim 200 \mathrm{hPa}$ in the tropics) is used to define the events and to view the accompanying propagation and breaking of Rossby waves, while time-averaged zonal wind fields are used to examine the basic flow field. Intrusion events are defined by first identifying high values of $\mathrm{PV}\left(|P V|>2 \mathrm{PVU} ; 1 \mathrm{PVU}=10^{-6}\right.$ $\mathrm{Ks}^{2} / \mathrm{kg}$ ) at $10^{\circ} \mathrm{N}$ or $10^{\circ} \mathrm{S}$. All such occurrences within $10^{\circ}$ longitude or within 6 days (the typical lifetime for events) are then grouped together as a single intrusion event. Each event is labeled by the first day and western-most longitude. 
(a) 30-doy mean U 350K

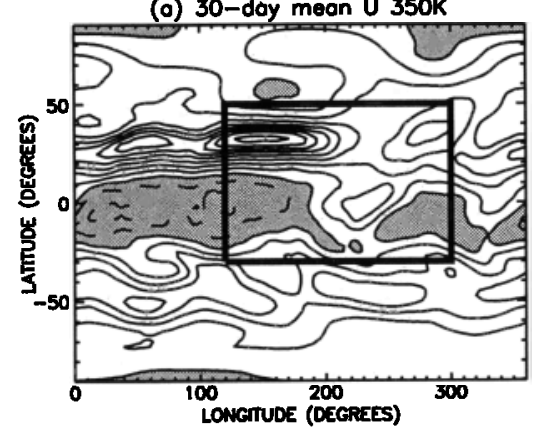

(d) PV $970130350 \mathrm{~K}$

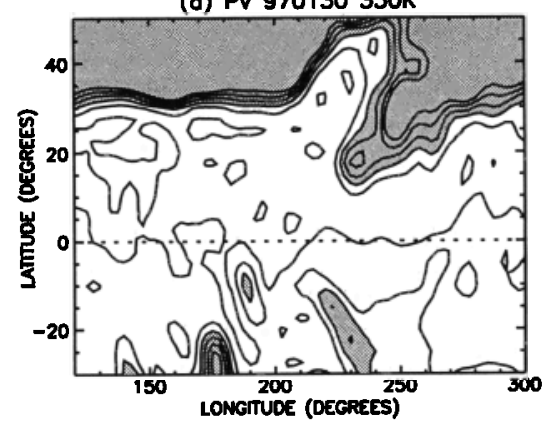

(b) PV $970126350 \mathrm{~K}$

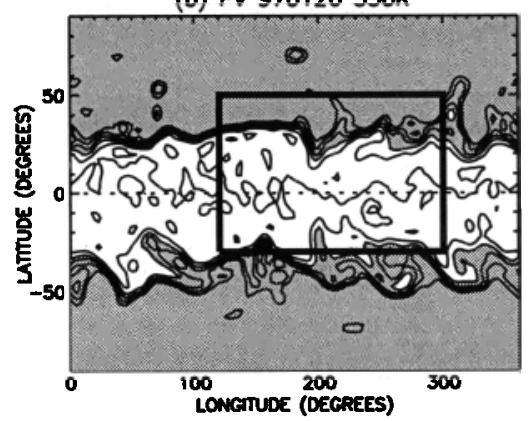

(c) pV $970131350 \mathrm{~K}$

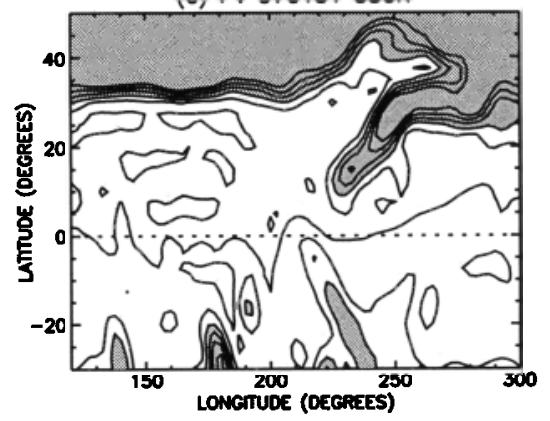

(c) PV $970128350 \mathrm{~K}$

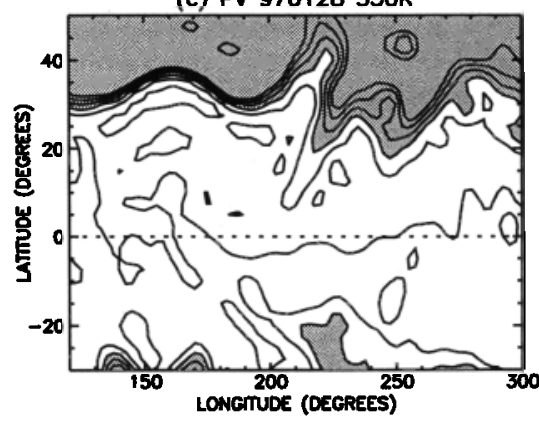

(f) PV $970201350 \mathrm{~K}$

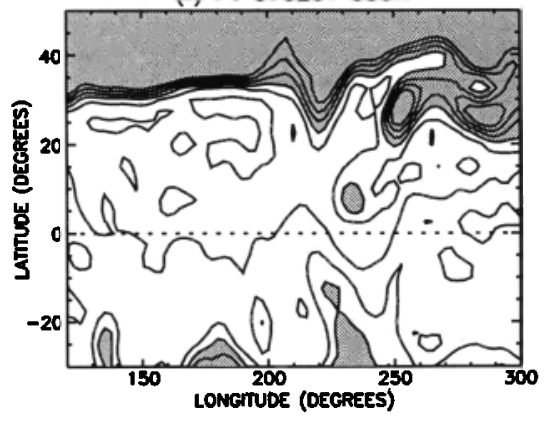

Figure 1. (a) zonal wind averaged between January 16 and February 14, 1997 (contour interval $10 \mathrm{~m} / \mathrm{s}$; negative values shaded). (b-f) PV on January 26 to February $1,1997(\mathrm{PV}=(-5,-4, \ldots, 5)$ PVU contoured, with $|P V|>2$ PVU shaded). All fields are on the $350 \mathrm{~K}$ isentrope.

Finally, events which involve only small isolated regions of high PV in the tropics are removed, to prevent blobs of high PV that are not immediately connected to a wave breaking event from been counted. To test the robustness of the climatology presented below, the analysis was repeated using 1.75 PVU as the critical value of PV, and the results were found to be very similar to those presented in this paper except for a slightly greater number of events.

\section{Results}

Figure 2 shows the resulting climatology of intrusion events (vertical bars, with northern hemisphere events shaded) together with the equatorial zonal winds (curves). The events occur predominantly during northern winter (Figure 2a) and over the Pacific $\left(180^{\circ}-260^{\circ} \mathrm{E}\right)$ and Atlantic $\left(310^{\circ}-\right.$ $360^{\circ} \mathrm{E}$ ) oceans, with events more frequent in the Pacific region (Figure 2b). Comparing the event frequency with the climatological equatorial zonal winds confirms the relationship between the occurrence of intrusion events and equatorial westerlies; the latter are present over the Pacific and Atlantic oceans during northern fall through spring, but not during summer. It should also be noted that there are simultaneous variations in the strength of the subtropical jet, with stronger diffluence in the jet exit region in the presence of stronger equatorial westerlies.

Figures $2 \mathrm{c}$ and $2 \mathrm{~d}$ show that there is a large interannual variability associated with intrusion events, particularly within the Pacific. The variability of Pacific events is strongly correlated with the phase of ENSO (correlation coefficient of -0.84 with the Nino 3.4 index), with fewer intrusion events in the warm phase (1982/83 and 1997/98 winters) than in the cold phase (1988/89 and 1998/99). This interannual variability is also consistent with changes in the zonal wind: During the warm phase there are weaker equa- torial westerlies, and also a stronger subtropical jet, in the Pacific, see curve in Figure 2c. The impact of ENSO on the Pacific UT flow and equatorward propagation of Rossby wave activity has been noted in previous studies [Tomas and Webster, 1994; Matthews and Kiladis, 1999]. The intrusion event climatology further suggests that ENSO impacts the lateral transport of tracers into and within the tropics.

Figure 2 shows that the spatial and temporal variations in the occurrence of intrusion events is similar in the northern and southern hemispheres. Furthermore, northern and southern intrusions often occur simultaneously; for a third of the NH events identified there is also a SH event in the same region. In Figure 1, for instance, the tip of a tongue of low PV can be seen in southern tropics just west of the northern hemisphere tongue (Figures $1 d$ and 1e) (see also Figure 2 of Tomas and Webster [1994]).

It is worth remarking that the seasonal variation of intrusion events in the NH climatology presented here is opposite to the one found by Postel and Hitchman [1999]. This is because their criteria were chosen to identify all wave breaking events on the subtropical tropopause, whereas our criteria are chosen to capture only those wave breaking events which transport stratospheric air directly into the deep tropics. Therefore, although the northern summer subtropical tropopause is more disturbed and exhibits more wave breaking than the winter tropopause [Postel and Hitchman, 1999], wave breaking events that transport high-PV air directly into the deep tropics occur predominantly during northern winter (when there are equatorial westerlies).

Finally, we note that the PV evolution during the majority of the intrusion events identified in our climatology is remarkably similar to that shown in Figure 1, with the disturbance amplification and wave breaking occuring in the jet exit region poleward of the equatorial westerlies. This is consistent with idealized modeling studies [Nakamura, 1994; Pe- 
(a)

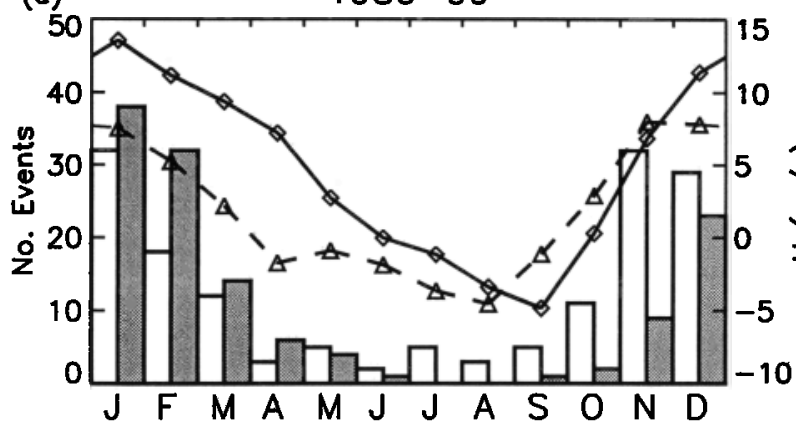

(c)

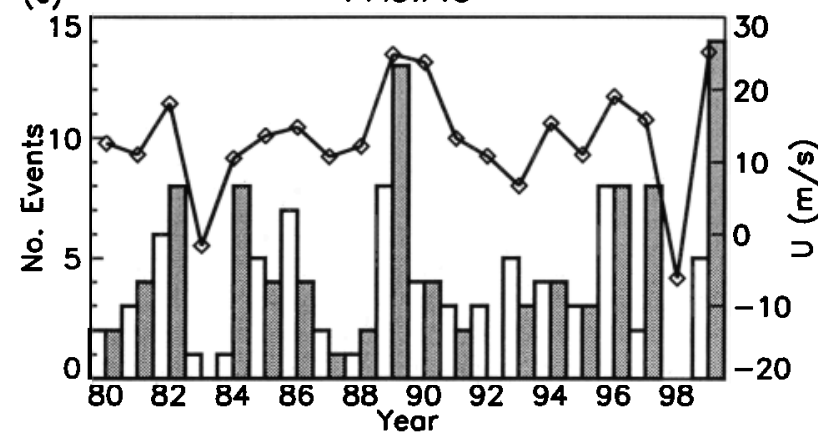

(b)

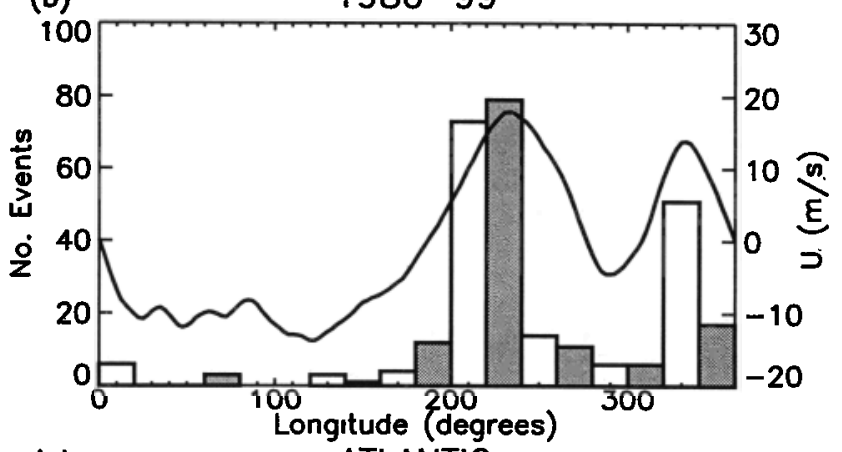

(d) ATLANTIC

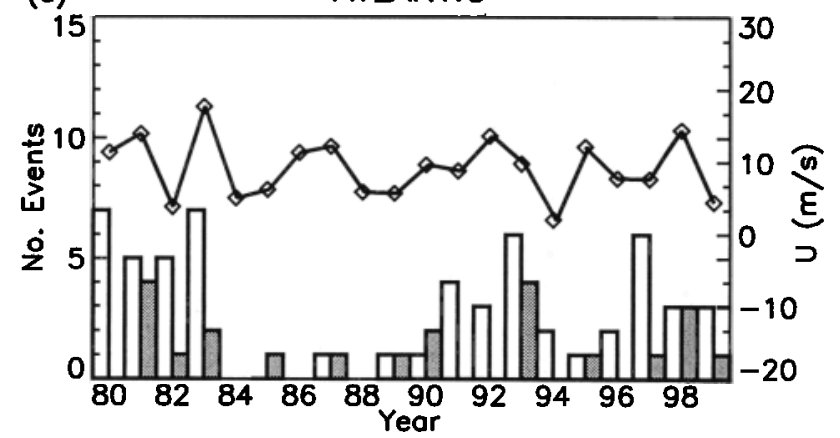

Figure 2. Histograms showing the number of intrusion events per (a) month, (b) longitude, and (c, d) year (NDJFM winter) for Pacific and Atlantic events, respectively. Note that in (c) and (d) " 80 " corresponds to the 1979/80 winter. The solid (unfilled) bars show northern (southern) hemisphere events. Curves correspond to climatological equatorial zonal winds at $350 \mathrm{~K}$ : (a) solid (dashed) curve is average over the Pacific (Atlantic) ocean, (b) DJF average, (c) average over Pacific, and (d) average over Atlantic.

ters and Waugh, 1996; Swanson et al., 1997]. Furthermore, examination of PV on other isentropes shows that these events transport extratropical air into the tropics in the middle troposphere (320K) and in the lower stratosphere (390$410 \mathrm{~K})$. Therefore, these intrusions may impact the moisture in the tropical middle and lower troposphere (and hence radiative balance and convection) as well the transport of air into the tropical stratosphere (see also [Horinouchi et al., 2000]).

\section{Concluding Remarks}

Intrusion events associated with Rossby wave breaking on the subtropical tropopause produce meridional transport of trace constituents, and also have been linked to tropical convection. It is thus plausible that the spatial and temporal variations in their frequency, which we have presented above, may cause similar variations in the distribution of trace constituents and convection. For example, the ENSOrelated variability in Pacific intrusions may contribute to the observed variability in tropospheric moisture over the tropical eastern Pacific during ENSO events [Bates et al., 1996; Newell et al., 1997]. Another interesting possibility is that the modulation of intrusion frequency by changes in the basic state may play some role in the water vapor feedback on climate. Changes in the upper tropospheric flow caused by climate change (e.g., frequency and intensity of ENSO events) may result in changes in the frequency of intrusions and, through changes in water vapor transport, subtropical moisture and climate [Pierrehumbert, 2000].

To test the above hypotheses it will be necessary to quantify the impact of the intrusion events on the tracer distri- butions. This will require a detailed analysis of the three dimensional flow during the events, including analysis of the fine-scale transport. Such an analysis is currently underway.

Acknowledgments. We thank Lenny Pfister and Rennie Selkirk for showing an animation of water vapor images that initiated this study, Takeshi Horinouchi for sharing unpublished results, and Steve Sherwood, George Kiladis, and Greg Postel for helpful discussions and comments.

\section{References}

Bates, J.J, X. Wu, and D.L. Jackson, Interannual variability of upper-troposphere water vapor band brightness temperature, J. Clim., 9, 427-438, 1996.

Brunet, G., and P.H. Haynes, Low-latitude reflection of Rossby Wave Trains. J. Atmos. Sci., 53, 482-496, 1996.

Folkins, I., M.Lowenstein, J. Podolske, S.J. Oltmans, and M. Profitt., A barrier to vertical mixing at $14 \mathrm{~km}$ in the tropics: Evidence from ozonesondes and aircraft measurements, $J$. Geophys. Res., 104, 22,095-22,102, 1999.

Horinouchi, T., F. Sassi, and B. Boville, Synoptic-scale Rossby waves and geographic distribution of lateral transport routes between the tropics and the extratropics in the lower stratosphere, J. Geophys. Res., to appear, 2000.

Kalnay, E., et al., 1996: The NCEP/NCAR 40-year reanalysis project, Bull. Am. Meteorol. Soc., 77, 437-471, 1996.

Kiladis, G.N., Observations of Rossby waves linked to convection over the eastern tropical Pacific. J. Atmos. Sci., 55, 321-339, 1998.

Kiladis, G.N., and K.M. Weickmann, Extratropical forcing of tropical Pacific convection during northern winter, Mon. Wea. Rev., 120, 1924-1938, 1992.

McIntyre, M.E., and T.N. Palmer, Breaking planetary waves in the stratosphere. Nature., 305, 593-600, 1983. 
Matthews A.J., and G.N. Kiladis, Interactions between ENSO, transient circulation, and tropical convection over the $\mathrm{Pa}$ cific.J. Climate, 12, 3062-3085, 1999.

Nakamura, M., Characteristics of potential vorticity mixing by breaking Rossby waves in the vicinity of a jet. Sc.D. thesis, 253pp, Massachusetts Institute of Technology, 1994.

Newell, R.E., Y. Zhu, W.G. Read, and J.W. Water, Relationship between tropical upper tropospheric moisture and eastern tropical Pacific sea surface temperature at seasonal and interannual time scales, Geophys. Res. Lett., 24, 25-28, 1997.

Numaguti, A., Characteristics of 4-to-20-day period disturbances observed in the Equatorial Pacific during the TOGA COARE IOP. J. Meteor. Soc. Japan., 73, 353-377, 1995.

Peters, D., and Waugh D.W., A. Influence of barotropic shear on the poleward advection of upper tropospheric air. J. Atmos. Sci., 53, 3013-3031, 1996.

Pierrehumbert, R., Lateral mixing as a source of subtropical water vapor. Geophys. Res. Lett., 25, 1784-1806, 1998.

Pierrehumbert, R., Subtropical water vapor as a mediator of rapid global climate change. In Clark PU, Webb RS and Keigwin LD eds. Mechanisms of global change at millennial time scales. American Geophysical Union Geophysical Monograph Series, 2000.

Postel, G.A., and M.H. Hitchman, A climatology of Rossby wave breaking along the subtropical tropopause. J. Atmos. Sc2., 56 , 359-373, 1999 .

Swanson K.L., P.J. Kushner, and I.M. Held, Dynamics of barotropic storm tracks., J Atmos. Sci., 54, 791-810, 1997.
Tomas, R., and P.J. Webster, Horizontal and vertical structure of Cross-equatorial wave propagation. J. Atmos. Sci., 51, 1417 $1430,1994$.

Waugh, D.W., L.M. Polvani, and R.A. Plumb, Nonlinear, barotropic response to a localized topographic forcing: formar tion of a 'tropical surf zone' and its effect on interhemispheric propagation, J. Atmos. Sci. 51, 1401-1416, 1994.

Webster, P.J., and J.R. Holton, Cross-equatorial response to middle-latitude forcing in a zonally varying basic state. $J$. Atmos. Sci. 39, 722-733, 1982.

Yang, G.Y., and B.J. Hoskins, Propagation of Rossby waves of nonzero frequency $J$. Atmos. Sci. 53, 2365-2378, 1996.

Yoneyama, K., and D.B., Parsons, A proposed mechanism for the intrusion of dry air into the tropical western pacific region. $J$. Atmos. Sci. 56, 1524-1546, 1999.

D. W. Waugh, Department of Earth and Planetary Science, Johns Hopkins University, Baltimore, MD 21218, USA. (email: waugh@jhu.edu)

L. M. Polvani, Department of Applied Physics and Applied Mathematics, Columbia University, New York, NY 10027, USA. (email: polvani@columbia.edu).

(Received August 23, 2000; revised October 10, 2000; accepted October 13, 2000.) 